\title{
EFEITOS DE MÉTODOS E ÉPOCAS DE CONTROLE DAS PLANTAS DANINHAS NA CULTURA DO MILHO ${ }^{1}$
}

\author{
JEFERSON ZAGONEL ${ }^{2}$, WILSON S. VENÂNCIO ${ }^{3}$ e RENI P. KUNZ ${ }^{4}$
}

\section{RESUMO}

Com o objetivo de avaliar os efeitos de diferentes épocas de controle de plantas daninhas, realizado através de capina manual ou aplicação de herbicidas, sobre a produtividade e características agronômicas do milho, foi instalado um experimento na Fazenda Escola "Capão da Onça” (UEPG), em Ponta Grossa-PR, no sistema de plantio direto na palha. $O$ delineamento experimental utilizado foi de blocos ao acaso, em esquema fatorial $2 \times 5$, com seis repetições. $\mathrm{O}$ híbrido utilizado foi XL 212, semeado no dia 11/11/97. Os herbicidas utilizados, com as respectivas épocas de aplicação, foram: atrazine $(1400+1400 \mathrm{~g} / \mathrm{ha})$, aos 2 e 19 dias após a emergência (DAE); atrazine + nicosulfuron (1400 $+12 \mathrm{~g} / \mathrm{ha}$ ), aos $8 \mathrm{DAE}$; atrazine + nicosulfuron $(1600+20 \mathrm{~g} / \mathrm{ha})$, aos 19
DAE; atrazine + nicosulfuron $(1000+40 \mathrm{~g} / \mathrm{ha})$, aos 26 DAE e nicosulfuron (60 g/ha), aos 31 DAE. As capinas manuais foram efetuadas nestas mesmas épocas. As plantas daninhas predominantes foram Brachiaria plantaginea, Triticum aestivum, Raphanus raphanistrum, Galinsoga parviflora e Richardia brasiliensis. Observou-se que o atraso na época de controle das plantas daninhas, a partir de dez DAE, afetou negativamente as características das plantas avaliadas, mais acentuadamente para o controle com herbicidas. Exceto o peso de 100 grãos, os demais componentes da produção e a produtividade diminuíram com o atraso na época de controle a partir de dez DAE.

Palavras chave: Zea mays L., matocompetição.

\section{ABSTRACT}

\section{Effect of methods and control time of weeds in maize crop}

With the objective of evaluating the effect of different timings of weed control performed by hand weeding or herbicide application, on the corn yield and agronomic characteristics, an experiment was set up on the "Capão da Onça" School Farm (UEPG) in Ponta Grossa - PR, under the no-tillage cropping system. The experimental arrangement employed was a randomized block design in a $2 \times 5$ factorial with six replications. The hybrid utilized was the XL 212, planted on 11/11/97. The herbicides used and their respective applications timings were: atrazine $(1400+$
$1400 \mathrm{~g} / \mathrm{ha})$ at 2 and 19 days after the emergence (DAE); atrazine + nicosulfuron $(1400+12 \mathrm{~g} / \mathrm{ha})$ at 8 DAE; atrazine + nicosulfuron $(1600+$ $20 \mathrm{~g} / \mathrm{ha})$ at $19 \mathrm{DAE}$; atrazine + nicosulfuron (1000 + $40 \mathrm{~g} / \mathrm{ha})$ at $26 \mathrm{DAE}$; and nicosulfuron $(60 \mathrm{~g} / \mathrm{ha})$ at $31 \mathrm{DAE}$. The hand weeding procedures being performed at the same timings. The predominant weeds were Brachiaria plantaginea, Triticum aestivum, Raphanus raphanistrum, Galinsoga parviflora and Richardia brasiliensis. It was observed that the delay in weed control timing from ten DAE onward negatively affected the

\footnotetext{
${ }^{1}$ Recebido para publicação em 13/08/98 e na forma revisada em 04/10/99.

${ }^{2}$ Prof. Adjunto, Dr., Dept ${ }^{\circ}$ de Fitotecnia e Fitossanidade - UEPG, Praça Santos Andrade s/n, CEP: 84.010-790, Ponta Grossa/PR.

${ }^{3}$ Prof. Assistente, MSc - UEPG.

${ }^{4}$ Eng $^{\text {O }}$ Agr $^{\circ}$, Novartis Biociências S/A, Av. Vicente Rao, 90, CEP: 04706-900 - São Paulo/SP.
} 
characteristics of the plants evaluated, more markedly so for the control through herbicides. Except for the weight of 100 kernels, the other components of yield and grain yield declined with the delay in control timing from ten DAE onward.

Key words: Zea mays L., weed competition.

\section{INTRODUÇÃO}

As plantas daninhas interferem no desenvolvimento das plantas de milho com intensidade variável em função da época de ocorrência, da população e das espécies presentes. A ocorrência de uma elevada população de invasoras no início do desenvolvimento da cultura, pode proporcionar perdas acentuadas na produtividade se o controle não for adequado e realizado nesta mesma época. Esta situação é frequentemente observada quando a dessecação no sistema de plantio direto, ou a gradagem no sistema convencional, são realizadas alguns dias antes da semeadura. Em ambos casos, quando a cultura emerge as plantas daninhas estão em estádios mais avançados de desenvolvimento, e assim, a população destas plantas irá determinar a época que o controle deve ser iniciado.

O período a partir da emergência da cultura, no qual esta pode conviver com as plantas daninhas sem a ocorrência de perdas de produtividade, foi denominado por Pitelli \& Durigan (1984) de período anterior à interferência (PAI). Este período, para o milho, varia de 15 a 25 dias (Blanco et al., 1976; Pitelli, 1985) e tende a ser menor quanto maior for a população de plantas daninhas (Ramos \& Pitelli, 1994; Blanco, 1996) e o período em que o controle anterior à semeadura foi realizado (Souza et al., 1996).

Quando as plantas daninhas são controladas na época recomendada, para cada cultura, a produtividade não é afetada pelo modo de controle, ou seja, através do uso de capinas manuais ou de herbicidas (Antuniassi \& Furlani Junior, 1994). Entretanto, na determinação da época de início do controle, ou do PAI, podem ocorrer diferenças para estes modos, visto a capina manual eliminar imediatamente as plantas daninhas, enquanto que com o uso de herbicidas, estas permanecem ainda por um período variável no local, competindo com a cultura. Para evitar esta competição, em lavouras tecnificadas, de alta produtividade, observa-se que o controle é efetuado precocemente através de aplicações sequenciais de herbicidas. Este procedimento permite a manutenção da lavoura livre de plantas daninhas por um maior período, evitando que estas interferiram negativamente na produtividade.

Este trabalho teve como objetivo avaliar os efeitos da época de controle de plantas daninhas, realizado através de capina manual ou aplicação de herbicidas, sobre a produtividade e características agronômicas do milho, cultivado no sistema de plantio direto na palha.

\section{MATERIAL E MÉTODOS}

O experimento foi instalado na Fazenda Escola "Capão da Onça" da UEPG, em Ponta Grossa-PR, no ano agrícola 1997/98, em Latossolo Vermelho Escuro de textura argilosa. O delineamento experimental utilizado foi de blocos ao acaso, em esquema fatorial 2 x 5 com seis repetições. Os tratamentos constaram de dois modos de controle de plantas daninhas (capina manual e aplicação de herbicidas) em cinco épocas $(2,8,19,26$ e 31 dias após a emergência do milho), definidas em função do estádio das plantas de Brachiaria plantaginea. O estádio da $B$. plantaginea na época das aplicações dos herbicidas em várias doses, encontram-se na Tabela 1. O estádio das demais plantas daninhas em cada época da aplicação dos herbicidas encontram-se na Tabela 2.

As capinas manuais foram realizadas nas mesmas datas das aplicações dos herbicidas. Para simular o efeito residual dos herbicidas, as parcelas foram capinadas sempre que apresentassem nível de reinfestação de $50 \%$ em relação à parcela correspondente tratada com herbicida. 
TABELA 1. Época de aplicação dos tratamentos, estádio de Brachiaria plantaginea e herbicidas com respectivas doses, utilizados no milho. Ponta Grossa-PR. 1997/98.

\begin{tabular}{lccc}
\hline Época de aplicação & Estádio de B. plantaginea & Herbicida & Dose $(\mathrm{g}$ i.a./ha) \\
\hline 02 DAE e 19 DAE $^{1}$ & até 2 folhas & atrazine + atrazine & $1.400+1.400$ \\
08 DAE & até 3 folhas & atrazine + nicosulfuron & $1.400+12$ \\
19 DAE & até 2 perfilhos & atrazine + nicosulfuron & $1.600+20$ \\
26 DAE & até 4 perfilhos & atrazine + nicosulfuron & $1.000+40$ \\
31 DAE & $>$ de 4 perfilhos & nicosulfuron & 60 \\
\hline
\end{tabular}

${ }^{1}$ Dias após a emergência; ${ }^{2}$ Primóleo; ${ }^{3}$ Sanson.

TABELA 2. Estádio das plantas daninhas em cada época de aplicação dos tratamentos de controle. Ponta Grossa-PR. 1997/98.

\begin{tabular}{lcccc}
\hline Época de & \multicolumn{4}{c}{ Estádio de desenvolvimento } \\
aplicação & T. aestivum & R. brasiliensis & R.raphanistrum & E. heterophylla \\
\hline 02 e 19 DAE & 2 folhas & 2 folhas & 2 folhas & 2 folhas \\
08 DAE & $\begin{array}{c}3 \text { folhas } \\
\text { início }\end{array}$ & 2 a 4 folhas & 2 a 4 folhas & 2 a 4 folhas \\
19 DAE & $\begin{array}{c}\text { perfilham. } \\
\text { perfilhamento }\end{array}$ & mais de 6 folhas & 4 a 6 folhas & 4 a 6 folhas \\
26 DAE & mais de 6 folhas & mais de 6 folhas \\
31 DAE & perf./elongação & mais de 6 folhas & mais de 7 folhas & mais de 6 folhas \\
\hline
\end{tabular}

${ }^{1}$ Dias após a emergência.

O híbrido utilizado foi o XL 212, semeado no dia 11/11/97, no sistema de plantio direto, sobre $3.2 \mathrm{t} / \mathrm{ha}$ de palha predominantemente de trigo. Adubou-se na semeadura, com $350 \mathrm{~kg} / \mathrm{ha}$ de adubo na fórmula comercial 04-22-22 e $100 \mathrm{~kg} / \mathrm{ha}$ de nitrogênio em cobertura, na forma de uréia, aos 20 dias após a emergência (DAE). $\mathrm{O}$ manejo das plantas daninhas (dessecação) foi realizado cinco dias antes da semeadura, através da aplicação de glyphosate $(1,2 \mathrm{~kg} / \mathrm{ha}$ de Roundup WG) + 2,4 D (0,8 1/ha de Esteron 400 $\mathrm{BR})$.

Os herbicidas foram aplicados através de pulverizador costal, à pressão constante de $30 \mathrm{lb} / \mathrm{pol}^{2}$, pelo $\mathrm{CO}_{2}$ comprimido, com bicos jato plano "leque" XR 110-02. Aplicou-se o equivalente à 200 1/ha de calda. As plantas daninhas presentes no experimento, avaliadas dois dias após a emergência do milho, foram:
Brachiaria plantaginea (capim-papuã), Triticum aestivum (trigo), Raphanus raphanistrum (nabo), Galinsoga parviflora (picão-branco) e Richardia brasiliensis (poaia) com, respectivamente 150 , 200, 34, 146 e 80 plantas por metro quadrado, em média.

Na época do florescimento, determinou-se a estatura de plantas, a altura da inserção da primeira espiga, o teor de clorofila (aparelho Minolta SPAD 501) e o peso das plantas secas. Na colheita foram avaliados os componentes da produção e a produtividade.

Os dados obtidos foram submetidos à análise de variância, sendo as diferenças entre as médias do modo de controle (capina manual e aplicação de herbicidas) comparadas pelo teste $\mathbf{t}$ ao nível de $5 \%$ de probabilidade e o efeito de época de controle, analisado através de regressão polinomial. 


\section{RESULTADOS E DISCUSSÃO}

Os herbicidas foram os mais usuais e recomendados na região (Almeida, 1991; Marochi, 1993) e, na sua maioria foram eficientes no controle das plantas daninhas presentes. Os tratamentos contendo atrazine apresentaram controle superior a $95 \%$ sobre todas as plantas daninhas avaliadas e o nicosulfuron, aplicado isoladamente, mostrou controle entre 50 e $70 \%$ para Richardia brasiliensis e Galinsoga parviflora e superior a $95 \%$ para as demais.

Não ocorreram interações significativas entre o modo e a época de aplicação dos tratamentos para o peso das plantas secas, o teor de clorofila, os componentes da produção e a produtividade.

A estatura de plantas, inserção da $1^{\text {a }}$ espiga, peso das plantas secas e teor de clorofila foram maiores para a capina manual quando comparada aos tratamentos com herbicidas (Tabela 3). Isto ocorreu em função da capina manual não proporcionar efeitos fitotóxicos nas plantas e por eliminar imediatamente todas as plantas daninhas, fator importante, uma vez que, nos tratamentos com herbicidas, as plantas daninhas permaneceram no local por alguns dias, competindo com a cultura. Somado a isto, o número de plantas daninhas presentes era elevado $\mathrm{e}$, para alguns tratamentos com herbicidas, nem todas foram controladas adequadamente. Entretanto, estas diferenças se refletiram somente no número de espigas por planta, visto os demais componentes da produção e a produtividade terem sido similares para as duas modalidades de controle (Tabela 4). Ressalta-se, que as condições climáticas ocorridas no experimento, de altas temperaturas e precipitação de $860 \mathrm{~mm}$ bem distribuídos da semeadura à colheita, aliadas às altas doses de adubo utilizadas, proporcionaram ótimas condições para o desenvolvimento das plantas de milho, mesmo para as afetadas pela competição com as plantas daninhas. Se estas condições não fossem tão adequadas, provavelmente os efeitos do atraso no controle se refletiriam em menor produção.

TABELA 3. Estatura de plantas, inserção da primeira espiga, peso das plantas secas e teor de clorofila de plantas de milho submetidas a diferentes modos de controle de plantas daninhas. Ponta Grossa-PR. 1997/98.

\begin{tabular}{lcccc}
\hline Modo de controle & $\begin{array}{c}\text { Estatura de plantas } \\
(\mathrm{cm})\end{array}$ & $\begin{array}{c}\text { Inserção da 1 } \\
\text { espiga }(\mathrm{cm})\end{array}$ & $\begin{array}{c}\text { Peso das plantas } \\
\text { secas }(\mathrm{g})\end{array}$ & $\begin{array}{c}\text { Teor de clorofila } \\
\left(\mathrm{g} / \mathrm{cm}^{2}\right)\end{array}$ \\
\hline Herbicidas & $186,7 \mathrm{~b}$ & $85.2 \mathrm{~b}$ & $72.3 \mathrm{~b}$ & $5.2 \mathrm{~b}$ \\
Capina manual & $203,8 \mathrm{a}$ & $104.0 \mathrm{a}$ & $82.1 \mathrm{a}$ & $5.5 \mathrm{a}$ \\
\hline Coef. de variação & $3,5 \%$ & $3.1 \%$ & $22.5 \%$ & $7.3 \%$ \\
\hline
\end{tabular}

Médias seguidas da mesma letra nas colunas, não diferem pelo teste $\mathbf{t}(\mathrm{p}>0.05 \%)$.

TABELA 4. Componentes da produção e produtividade do híbrido de milho XL 212 submetido a diferentes modos de controle de plantas daninhas. Ponta Grossa-PR. 1997/98.

\begin{tabular}{lccccc}
\hline Modo de controle & $\begin{array}{c}\text { Plantas } / \mathrm{m}^{2} \\
\left(\mathrm{n}^{\circ}\right)\end{array}$ & $\begin{array}{c}\text { Espigas/planta } \\
\left(\mathrm{n}^{\circ}\right)\end{array}$ & $\begin{array}{c}\text { Grãos/espiga } \\
\left(\mathrm{n}^{\circ}\right)\end{array}$ & $\begin{array}{c}\text { Peso/100 } \\
\text { grãos }(\mathrm{g})\end{array}$ & $\begin{array}{c}\text { Produtividade } \\
(\mathrm{kg} / \mathrm{ha})\end{array}$ \\
\hline Herbicidas & $6,4 \mathrm{a}$ & $0,97 \mathrm{~b}$ & $394 \mathrm{a}$ & $25,3 \mathrm{a}$ & $6.945 \mathrm{a}$ \\
Capina manual & $6,1 \mathrm{a}$ & $1,01 \mathrm{a}$ & $415 \mathrm{a}$ & $25,8 \mathrm{a}$ & $7.145 \mathrm{a}$ \\
\hline Coef. de variação & $9,3 \%$ & $6,8 \%$ & $10,2 \%$ & $12,1 \%$ & $11,3 \%$ \\
\hline
\end{tabular}

Médias seguidas da mesma letra nas colunas, não diferem pelo teste $\mathbf{t}(\mathrm{p}>0.05 \%)$. 
Quanto à época de controle, observou-se (Figura 1) uma função quadrática para a estatura de plantas e a inserção da primeira espiga, que diminuíram com o atraso na época de controle a partir de dez dias após a emergência (DAE) e, para ambas características, o controle com herbicidas apresentou valores menores do que os observados para a capina manual. $\mathrm{O}$ peso das plantas secas e o teor de clorofila diminuíram linearmente com o atraso na época de controle, independente do modo de aplicação. Quando as plantas são afetadas em seu porte, ou uma parte da planta é retirada ou danificada, a tendência é um aumento na eficiência por unidade da área remanescente em realizar a fotossíntese e, em geral, esta área apresenta uma coloração verde mais escuro, como consequência do aumento no teor de clorofila. No presente trabalho, a estatura e o peso das plantas foi menor quando se atrasou a época de controle e, portanto, era de se esperar que o teor de clorofila se mantivesse constante ou até aumentasse. Entretanto, a diminuição neste teor, ocorrida com o atraso na época de controle, ocorreu provavelmente em função da concorrência das plantas daninhas com a cultura, especialmente por nitrogênio, que segundo Blanco et al. (1974) e Blanco et al. (1978) é o elemento mais intensamente solicitado pela maioria das plantas daninhas. Resultados similares foram obtidos por Souza (1996), que observou menores valores para o teor de clorofila, a estatura de plantas e a inserção da primeira espiga quando do não controle das plantas daninhas em relação ao controle até 45 DAE.

A consequência dos efeitos da matocompetição nas características estudadas, refletiu-se nos componentes da produção e na produtividade (Figura 2), onde observa-se que o número de plantas por área apresentou uma diminuição acentuada a partir de 20 DAE e o número de espigas por planta diminuiu linearmente com o atraso na época de controle.
Resultados similares foram obtidos por Ramos e Pitelli (1994), que observaram redução no número de espigas por planta com o atraso na época de controle, porém, o número de plantas por área não foi afetado. Em razão da matocompetição ter ocorrido após o estabelecimento do milho, seus efeitos negativos vieram a incidir sobre o número de espigas por planta, que mostrou-se um componente importante na determinação da produtividade. $\mathrm{O}$ número de fileiras apresentou uma diminuição com a época de controle a partir de cinco DAE, enquanto o número de grãos por fileira diminuiu a partir de quinze DAE. Assim, o número de grãos por espiga, que é função dos dois anteriores, apresentou um valor intermediário entre estes e diminuiu quando o controle ocorreu após dez DAE. Para o peso de 100 grãos, nenhuma equação de regressão se adaptou ao comportamento observado. Como o número de espigas e de grãos por espiga foram menores para o controle mais tardio e as condições climáticas foram favoráveis ao desenvolvimento do milho durante a fase de enchimento de grãos, o único componente passível de aumento foi o peso de 100 grãos, fato que explica o maior valor observado aos 26 DAE, em relação aos 8 DAE.

A produtividade diminuiu com o atraso na época de controle a partir de dois até oito DAE. A parti daí, até dezoito DAE, ocorreu uma leve diminuição na produtividade, que diminuiu acentuadamente a partir desta data. Estes resultados indicam uma vantagem do controle precoce das plantas daninhas sobre a produtividade, que quando realizada aos dois DAE, já mostra resultados positivos. Para as condições de alta infestação de plantas daninhas ocorridas, o atraso na época de controle a partir de dez DAE afetou negativamente as características das plantas avaliadas, mais acentuadamente para a capina com herbicidas. À exceção do peso de 100 grãos, os demais componentes da produção e a produtividade diminuíram com o atraso na época de controle a partir de dez DAE. 
Estatura de plantas (cm)

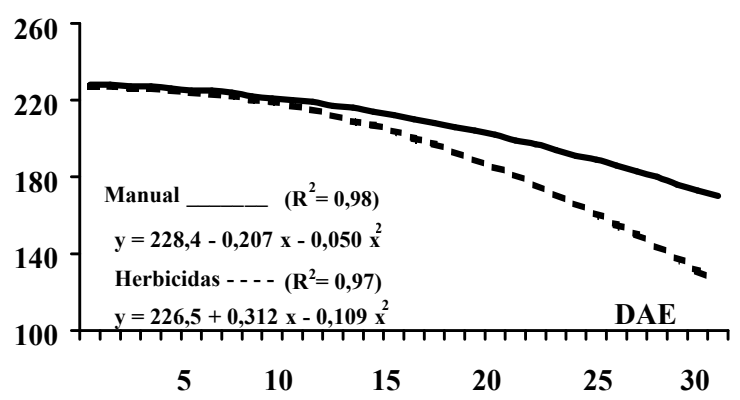

Peso/planta (g)

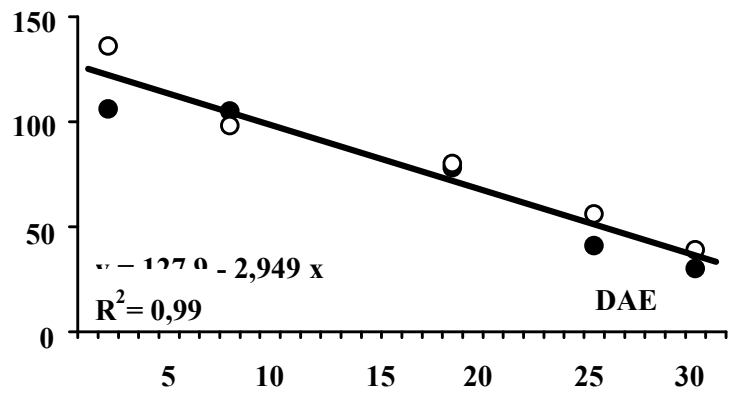

Inserção da $1^{\text {a }}$ espiga (cm)

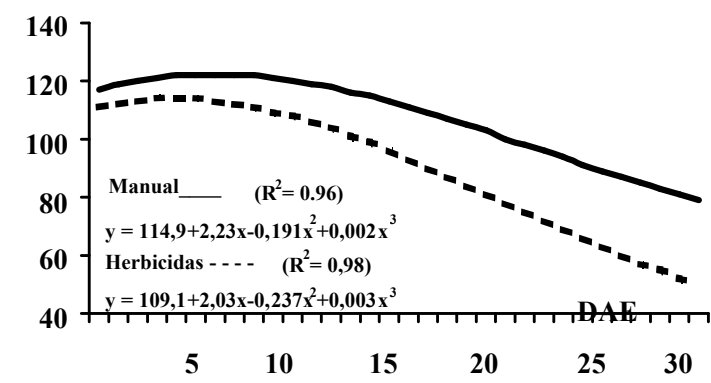

Teor de clorofila $\left(\mathrm{mg} / 100 \mathrm{~cm}^{2}\right)$

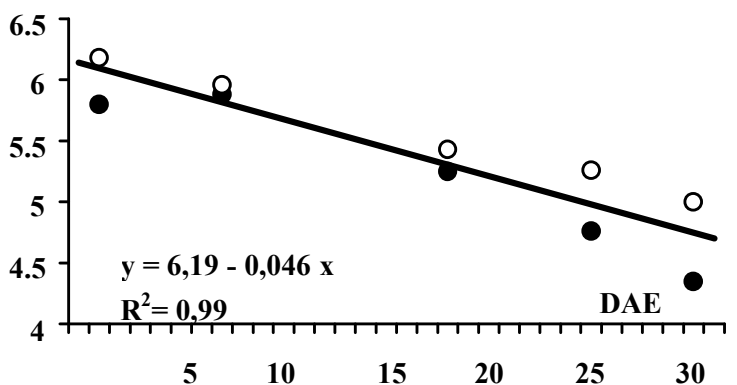

$\mathrm{DAE}=$ dias após a emergência; $\bullet$ = capina manual; $\mathbf{O}=$ herbicidas

FIGURA 1. Estatura de plantas, inserção da primeira espiga, peso das plantas secas e teor de clorofila das plantas de milho do híbrido XL 212, em função da época de controle de plantas daninhas. Fazenda Escola-UEPG. Ponta Grossa - PR. 1997/98. 


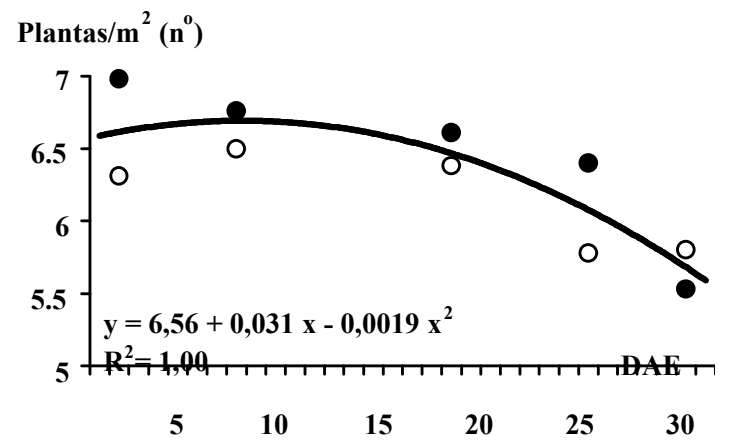

Espigas/planta $\left(\mathbf{n}^{0}\right)$
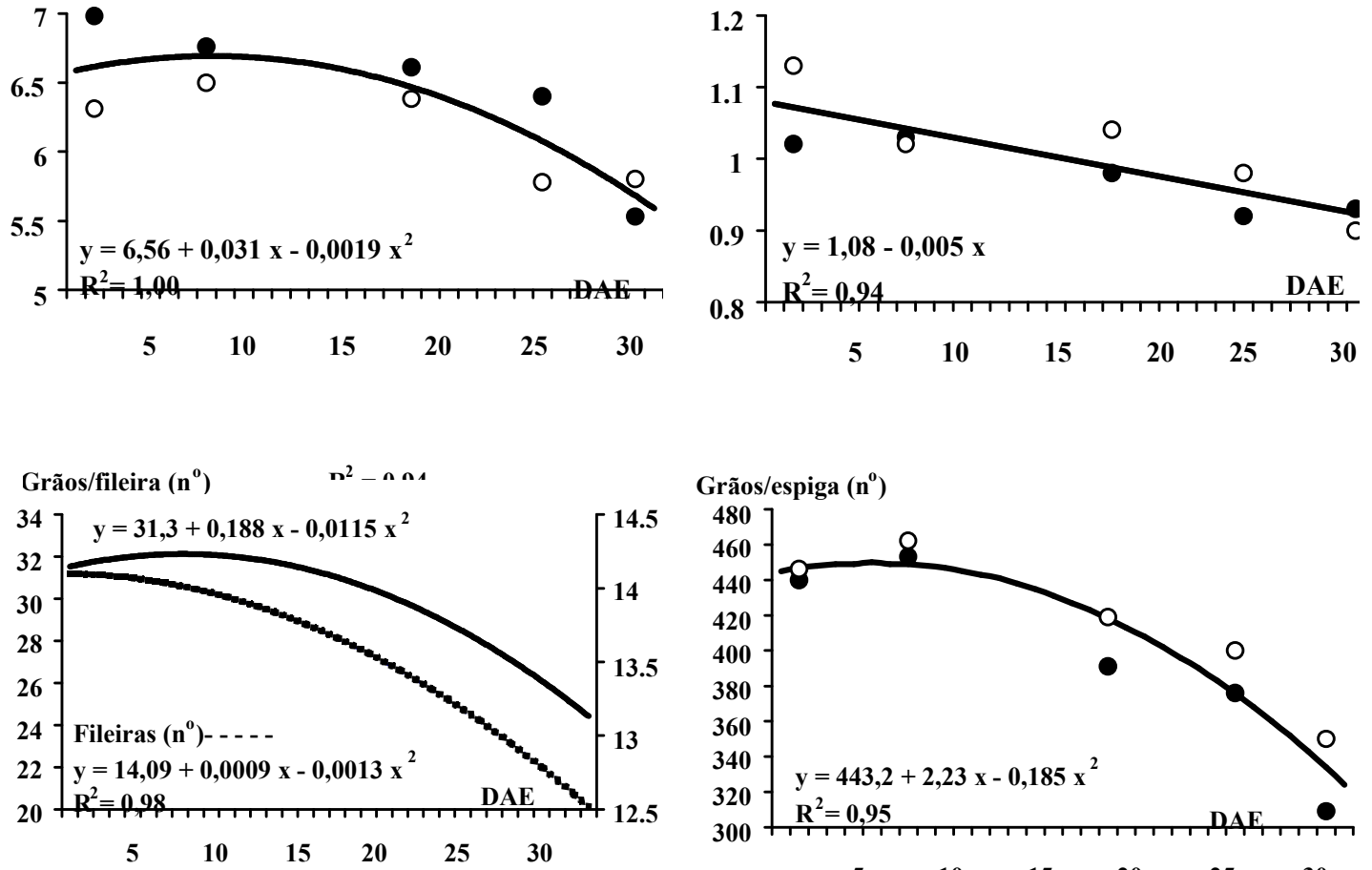

Peso/100 grãos (g)
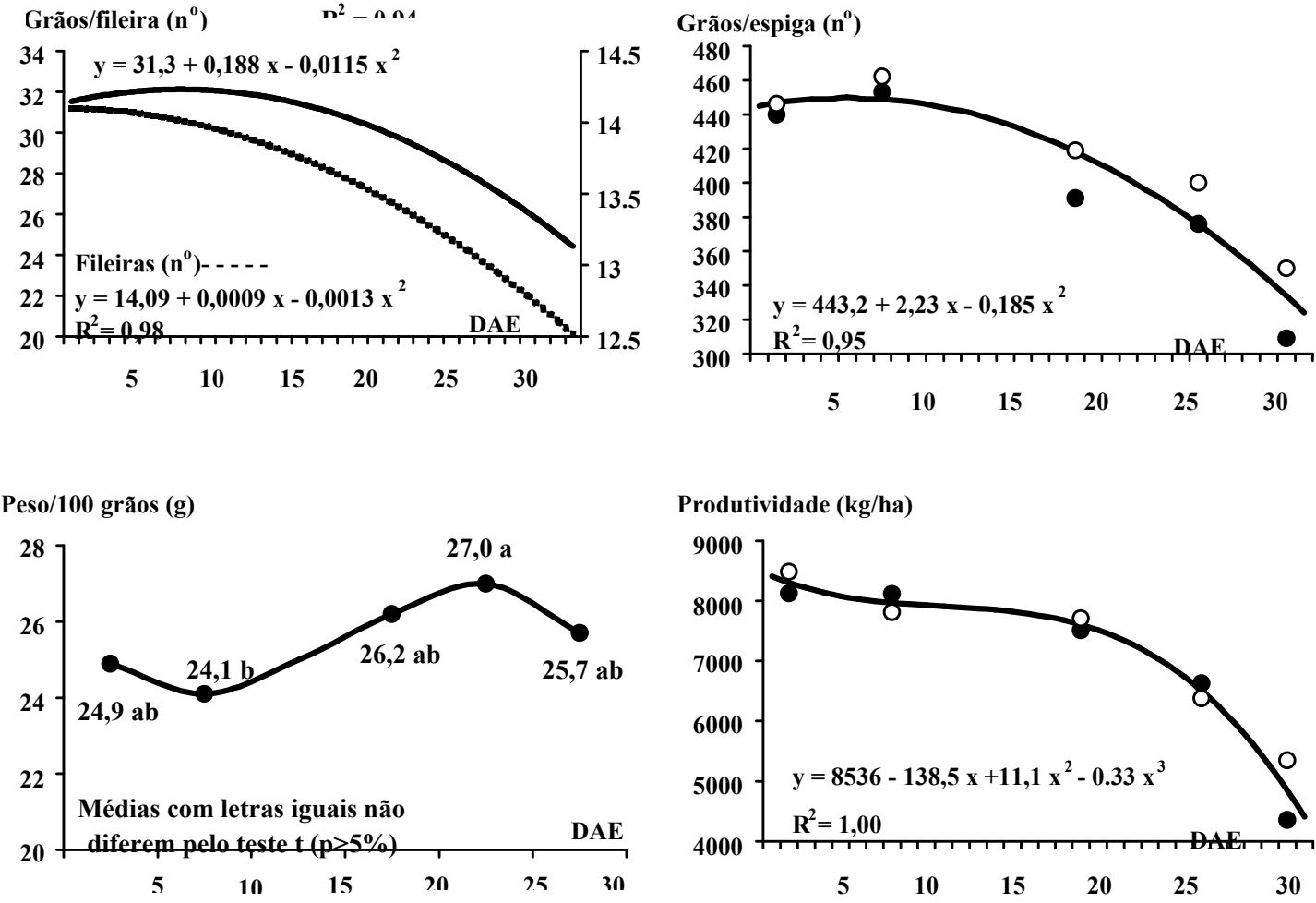

$\mathrm{DAE}=$ dias após a emergência; $\bullet=$ capina manual; $\mathbf{O}=$ herbicidas

FIGURA 2. Componentes da produção e produtividade do híbrido de milho XL 212 em função da época de início de controle de plantas daninhas. Fazenda Escola - UEPG. Ponta Grossa - PR. 1997/98. 


\section{LITERATURA CITADA}

ALMEIDA, F.S. Plantas daninhas e seu controle. In: A cultura do milho no Paraná. Londrina, 1991, p. 141-184. (IAPAR. Circular, 68).

ANTUNIASSI, U.R. \& FURLANI JÚNIOR, J.A. Simulação econômica comparativa entre o controle químico e mecânico das plantas daninhas na cultura do milho (Zea mays L.) semeado em janeiro. Energia na Agricultura, v.9, n.1, p.18-36. 1994.

BLANCO, H.G.; HAAG, H.P.; OLIVEIRA, D.A. Estudo sobre a competição de plantas daninhas na cultura do milho (Zea mays L.). II - Influência do mato na nutrição do milho. Arq. Inst. Biol., v.41, n.1, p.5-14, 1974.

BLANCO, H.G.; ARAÚJO, J.B.M.; OLIVEIRA, D.A. Estudo sobre a competição de plantas daninhas na cultura do milho (Zea mays L.). IV - Determinação do período de competição. Arq. Inst. Biol., v.43, n.3/4, p.105-14, 1976.

BLANCO, H.G.; HAAG, H.P., J.B.M.; OLIVEIRA, D.A. Estudo sobre a competição de plantas daninhas na cultura do milho (Zea mays L.). V - Influência da adubação nitrogenada no grau de competição. Arq. Inst. Biol., v.45, n.1, p.13-24, 1978.

BLANCO, H.G. Base biológica para manejo de plantas daninhas na cultura do milho. Arq. Inst. Biol., v.58, n.1, p.1-5, 1996.

MAROCHI, A.I. Controle de infestantes na cultura do milho em sistema de plantio direto. Rev. Batavo, ano II, n.22, p.19-24, 1993.

PITELLI, R.A. e DURIGAN, J.C. Terminologia para períodos de controle e de convivência das plantas daninhas em culturas anuais e bianuais. In: CONGRESSO BRASILEIRO DE HERBICIDAS E PLANTAS DANINHAS, 15, 1984, Belo Horizonte. Resumos... Belo Horizonte: SBHED, 1984.p.37.

PITELLI, R.A. Interferência das plantas daninhas nas culturas agrícolas. Inf. Agrop., v.11, n.129, p.16-27, 1985.

RAMOS, L.R.M. \& PITELLI, R.A. Efeitos de diferentes períodos de controle da comunidade infestante sobre a produtividade da cultura do milho. Pesq. Agrop. Bras., v.29, n.10, p. 1523-31, 1994.

SOUZA, L.C.F.; CRUZ, J.C.; RAMALHO, A.P.; SALVADOR, N.; SILVA, J.B. Efeito da antecedência da gradagem ao plantio do milho no controle de plantas daninhas. Pesq. Agrop. Bras., v.31, n.11, p. 789-93, 1996.

SOUZA, J.R.P. Período de controle das plantas daninhas, crescimento e produtividade da cultura do milho (Zea mays L.). Botucatu, FCA/UNESP. 1996. 91p. (Tese de doutorado). 